\title{
Characteristics of an Intense Neutron Source Based on the $d+B e$ Reaction
}

\author{
M. J. Saltmarsh \\ C. A. Ludemann \\ C. B. Fulmer \\ R. C. Styles
}




\section{DISCLAIMER}

This report was prepared as an account of work sponsored by an agency of the United States Government. Neither the United States Government nor any agency Thereof, nor any of their employees, makes any warranty, express or implied, or assumes any legal liability or responsibility for the accuracy, completeness, or usefulness of any information, apparatus, product, or process disclosed, or represents that its use would not infringe privately owned rights. Reference herein to any specific commercial product, process, or service by trade name, trademark, manufacturer, or otherwise does not necessarily constitute or imply its endorsement, recommendation, or favoring by the United States Government or any agency thereof. The views and opinions of authors expressed herein do not necessarily state or reflect those of the United States Government or any agency thereof. 


\section{DISCLAIMER}

Portions of this document may be illegible in electronic image products. Images are produced from the best available original document. 
Printed in the United States of America: Available from

National Technical Information Service

U.S. Department of Commerce

5285 Port Royal Road, Springfield, Virginia 22161

Price: Printed Copy $\$ 4.00 ;$ Microfiche $\$ 2.25$

This report was prepared as an account of work sponsored by the United States Government. Neither the United States nor the Energy Research and Development Administration/United States Nuclear Regulatory Commission, nor any of their employees, nor any of their contractors, subcontractors, or their employees, makes any warranty, expeess ur implled, or assumes any legal liability or responsibility for the accuracy, oompletencss on uselulıess of any information, apparatus, product or process disclosed, or represents that its use would not infringe privately owned rights. 
ORNL/TM-5696

Contract No. W-7405-eng-26

Physics Division

CHARACTERISTICS OF AN INTENSE NEUTRON SOURCE

BASED ON THE $d+$ Be REACTION

M. J. Saltmarsh

C. A. Ludemann

C. B. Fulmer

R. C. Styles

Date Published: November 1976

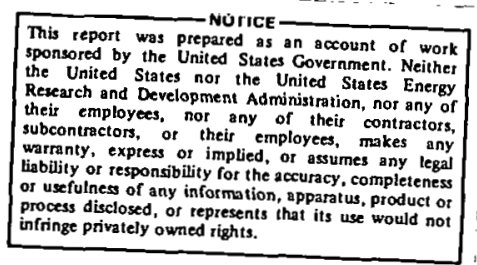

NOTICE This document contains information of a preliminary nature and was prepared primarliy for internal use at the Uak Hidge INariunal Laboratory. It is subject to revision or correction and therefore does not represent a final report.

OAK RIDGE NATIONAL LABORATORY

Oak Ridge, Tennessee $\mathbf{3 7 8 3 0}$

uperated by

UNION CARBIDE CORPORATION

for the

ENERGY RESEARCH AND DEVELOPMENT ADMINISTRATION 


\section{THIS PAGE \\ WAS INTENTIONALLY \\ LEFT BLANK}


CONTENTS

$\underline{\text { Page }}$

ACKNOWLEDGMENTS ......................

ABSTRACT ......................... . . . . 1

INTRODUCTION . . . . . . . . . . . . . . . . . . . 1

SOURCE DESIGN . . . . . . . . . . . . . . . . 2

NEUTRON YIELDS FROM THE $d+$ Be REACTION . . . . . . . . . 4

TIME-OF-FLIGHT MEASUREMENT . . . . . . . . . . . . . . 4

FOIL ACTIVATION MEASUREMENTS . . . . . . . . . . . 7 7

DOSIMETRY FOR THE $d+$ Be NEUTRON SOURCE . . . . . . . . . 8

NEUTRON YIELDS FROM THE d + Li REACTION . . . . . . . . 12

REFERENCES . . . . . . . . . . . . . . . . 13

TABLES ......................... 15

FIGURES . . . . . . . . . . . . . . . . . . 21 
THIS PAGE

\section{WAS INTENTIONALLY \\ LEFT BLANK}




\section{ACKNOWLEDGMENTS}

Our thanks are due to G. J. Smith for help in the early steps of this work, and to R. P. Cumby for providing the neutron scintillation detector. The invaluable assistance of $M$. B. Marshall and the ORIC operating staff is gratefully acknowledged. One of us (RCS) would like to thank Oak Ridge Associated Universities for support as an Undergraduate Research Trainee. 
CHARACTERISTICS OF AN INTENSE NEUTRON SOURCE

BASED ON THE $d+$ Be REACTION

M. J. Saltmarsh

C. A. Ludemann

C. B. Fulmer

R. C. Styles*

ABSTRACT

\begin{abstract}
A neutron source designed for fusion-related radiation damage studies has been built based on the $\mathrm{d}+\mathrm{Be}$ reaction. Using a $40 \mathrm{MeV}, 20 \mu \mathrm{A}$ deuteron beam from the Oak Ridge Isochronous Cyclotron neutron fluxes of $1-2 \times 10^{12} \mathrm{n} / \mathrm{cm}^{2} / \mathrm{sec}$ are obtained over an area $\sim 50 \mathrm{~mm}^{2}$. The design of the source is described, together with time-of-flight and activation foil measurements of the thick target neutron yields from the ${ }^{9} \mathrm{Be}(\mathrm{d}, \mathrm{n})$ reaction for the angular range from $0^{\circ}$ to $90^{\circ}$. A dosimetry procedure based on these measurements is presented. In addition time-of-flight measurements. of the thick target neutron yields for the $L i(d, n)$ reaction are reported and compared with the ${ }^{9} \mathrm{Be}(\mathrm{d}, \mathrm{n})$ results.
\end{abstract}

\title{
1. Introduction
}

One of the major concerns of the fusion power technology program is the radiation damage to structural materials caused by the neutrons emitted from a D-T plasma. ${ }^{1}$ ) The high energy ( $\sim 14 \mathrm{MeV}$ ) component in a fusion reactor first wall neutron spectrum is expected to produce radiation effects different from those encountered in fission reactors due primarily to the higher yield of nuclear transmutation products, particularly helium. Studies of these radiation effects will require the use of neutron sources with suitable spectral characteristics. Until recently most source development work has been concentrated on the use of the $D+T$ reaction, and neutron fluxes up to $10^{12} \mathrm{n} / \mathrm{cm}^{2} / \mathrm{sec}$ are available at facilities such as the rotating target source reported by Booth and Barshal1. ${ }^{2}$ )

*Oak Ridge Associated Universities Undergraduate Research Trainee from Berry College; present address: University of Georgia, Athens, Georgia. 
In this paper we describe a $d+B e$ neutron source based on a $40 \mathrm{MeV}$ deuteron beam from the Oak Ridge Isochronous Cyclotron (ORIC) which provides neutron fluxes of up to $2 \times 10^{12} \mathrm{n} / \mathrm{cm}^{2} / \mathrm{sec}$. The source has been used for a number of fusion-related irradiations ${ }^{3,4}$ ) and has proved to be reliable and easy to operate. Absolute measurements of the neutron yield and energy spectrum from the $d+B e$ reaction were made, and the results used in the development of dosimetry techniques suited to this type of source.

While sources of this type can provide reasonable intensities by today's standards, future materials studies will require far more powerful devices. Efforts are now being made to develop such sources based on both the $D+T$ reaction ${ }^{5,6}$ ) and the $d+\operatorname{Li}$ reaction. ${ }^{7,8,9,10}$ ) Because of ORNL's interest in $d+L i$ sources, we have also measured the neutron yields from this reaction and have found them to be very similar to those from the $d+$ Be reaction. The dosimetry techniques described in this work should therefore be applicable to the proposed $d+$ Li sources.

\section{Source Design}

A schematic drawing of the beryllium target assembly is shown in Fig. 1. The target itself is machined from a cylinder of beryllium $38 \mathrm{~mm}$ in diameter and $38 \mathrm{~mm}$ long. A $12.7 \mathrm{~mm}$ diameter hole is bored along the axis of the cylinder to within $6.3 \mathrm{~mm}$ of the end, thereby leaving just enough material to stop the $40 \mathrm{MeV}$ deuceron beam. The beryllium is surrounded by a copper water-cooled jacket, and springloaded against a tantalum plate which forms the end-window of the cylotron beam-pipe vacuum system. The tantalum plate is thick enciigh $(2.3 \mathrm{~mm})$ to stop any protons from the ${ }^{9} \mathrm{Be}(\mathrm{d}, \mathrm{p})$ reaction.

A quadrupole doublet placed approximately $70 \mathrm{~cm}$ upstream of the target, focusses the beam through a $12.7 \mathrm{~mm}$ diameter tantalum collimator and onto the target itself. The quadrupole current is set to produce a focus at the position of the sample to be irradiated 
rather than at the target, a procedure which produces the maximum neutron flux on the sample. At the maximum beam level, which is limited to $20 \mu \mathrm{A}$ due to activation of the cyclotron extraction system, the beam lost to the tantalum collimator is $\approx 30 \mathrm{nA}$, and the diameter of the beam spot at the target is $\lesssim 5 \mathrm{~mm}$.

Figure 2 shows the entire source assembly mounted on a sliding table (1) which permits movement along the beam axis. The sliding seal which connects to the cyclotron beam pipe is at the left (2); a remotely operated target ladder (5) permits insertion of a viewing phosphor at the position of the tantalum collimator. The Be target, copper jacket and tantalum end-plate are all mounted on a stainless steel flange (3) to which the cooling water lines are attached. Also shown is a removable high vacuum chamber (4) which was used to hold samples in a neutron sputtering measurement ${ }^{3}$ ).

The procedure in setting up for an experiment is to insert the phosphor in place of the tantalum.collimator and slide the whole source assembly along the beam direction until the phosphor is located at the position of the sample to be irradiated. Using a low beam intensity ( $~ 1 . \mathrm{nA}$ ) the beam optics are adjusted to provide the smallest possible leam spot on the phosphor and the source assembly. is then returned to its normal position. The phosphor is replaced by the tantalum collimator and the beam intensity increased to $20 \mu \mathrm{A}$. At this higher beam level the increased load on the cyclotron extraction system results in small changes of the beam trajectory from the cyclotron. Steering magnets are therefore used to re-center the beam by minimizing the beam lost to the collimator.

An irradiation typically lasts 8 - 36 hours with slow beam intensity variations $\approx 10 \%$ occurring during the irradiation period. ' In addition some interruptions of the beam occur, most being due to sparks in the cyclotron R.F. and extraction systems resulting in loss of beam for periods of seconds with a frequency varying between $\sim 0.1$ /hour to $\sim 1 /$ hour. Calculations indicate that the thermal expansion of the beryllium due to beam heating is sufficient to cause plastic deformation 
of the target near the interaction region, so these beam interruptions will eventually result in mechanical failure of the target. However, after a total of approximately 300 hours of bombardment with an estimated $10^{2}$ beam interruptions no observable damage has occurred except on one occasion when the cooling water was inadvertently valved off. The maximum beam which the target can withstand before melting is not known. In an early run the beam current was increased to $25 \mu \mathrm{A}$ for a short time ( $\sim \mathrm{min}$ ) to ensure that some margin of safety existed at the normal operating level. Again no observable damage urcisyned.

\section{Neutron Yields from the $d+$ Be Reaction}

During an irradiation the total beam on the target is monitored to provide an indication of the neutron flux on the irradiated samples. However, beam integration does not provide an adequate measure of fluence at a given point on a sample. The samples are generally very close (a few $\mathrm{mm}$ ) to the beryllium target and the geometry is poorly defined. Furthermore, the spatial variation in neutron flux is quite rapid. At a distance of $5 \mathrm{~mm}$ from the tantalum end-plate the measured neutron intensity profile is roughly gaussian in shape, with a full width at half maximum $\sim 8 \mathrm{~mm}$. We, therefore, use cobalt and nickel activation foils placed near the sample position to obtain the required dosimetry information, including the spatial variation of the neutron intensity and energy spectrum. The neutron yield measurements used to calibrate these activation foils are described below.

\subsection{Time-of-F1ight Measurements}

The time-of-flight (TOF) measurements were made using a $40.1 \mathrm{MeV}$ deuteron beam from the ORIC. This beam is pulsed at the cyclotron orbital frequency of $12.97 \mathrm{MHZ}$, providing 2ns wide pulses every 77.01 ns. With the maximum available flight-path of $3 \mathrm{~m}$ the resultant energy 
resolution varied from $\sim 4 \%$ at a neutron energy of $5 \mathrm{MeV}$ to $\sim 15 \%$ at $40 \mathrm{MeV}$. However, neutron energies below $5 \mathrm{MeV}$ could not be reliably measured with this flight path because of overlapping events from successive beam bursts. Accordingly most of the measurements were repeated using a flight path of $0.75 \mathrm{~m}$, which allowed the data to be extended down to $\mathrm{E}_{\mathrm{n}} \sim 2 \mathrm{MeV}$.

The experimental arrangement is shown in Fig. 3. The deuteron beam passed through a thin $\left(7.5 \mathrm{mg} / \mathrm{cm}^{2}\right)$ gold scattering foil, used in monitoring the beam, and onto the thick $(6.3 \mathrm{~mm})$ beryllium target. Neutrons and gamma-rays emitted at an angle $\theta$ were detected in a cylindrical cell of NE213 liquid scintillator ${ }^{11}$ ) $37.3 \mathrm{~mm}$ in diameter by $34.1 \mathrm{~mm}$ long viewed by a 56AVP photomultiplier tube. The fast timing signal from the photomultiplier tube was used to start a time-to-amplitude converter, the stop signal being derived from every second cycle of the cyclotron RF. A neutron-gamma discrimination circuit was used to route an event into one of two 400-channel time-of-flight spectra. Background events, for example neutrons scattered from the experimental room floor or walls, were measured by placing a $20 \mathrm{~cm}$ thick lead shadow shield mid-way between the target and the detector. When the lead shield was removed it was displaced by the smallest possible distance $(6 \mathrm{~cm})$, so that the effect of in-scattering from the lead was similar for both foreground and background runs.

The beam current required for these measurements was small, $\lesssim 0.1 \mathrm{nA}$. The beam was monitored by counting deuterons scattered at $\pm 45^{\circ}$ from the thin gold foil. Two detectors were used to eliminate errors due to movements of the beam spot on the gold foil. This secondary monitor was calibrated at intervals during the experiment by inereasing the beail current and using the second scattering chamber as a Faraday Cup.

The neutron detector threshold was set relative to the half-height of the Compton edge from a ${ }^{22} \mathrm{Na}$ source. Following the definitions of 
Verbinski et al. ${ }^{12}$ this corresponds to 0.89 light units (LU). For the $3 \mathrm{~m}$ runs the threshold was set to be $1.00 \mathrm{LU}\left(\mathrm{E}_{\mathrm{n}} \sim 3.5 \mathrm{MeV}\right)$, while for the $0.75 \mathrm{~m}$ data a setting of $0.266 \mathrm{LU}\left(\mathrm{E}_{\mathrm{n}} \sim 1.3 \mathrm{MeV}\right)$ was used. The detector efficiency at each threshold was calculated for a number of neutron energies in the range $1-50 \mathrm{MeV}$, using the Monte Car 10 code $05 \mathrm{~S}^{13}$ ).

For data analysis the positions of the two gamma-peaks in the appropriate spectrum were obtained by fitting a gaussian peak to the data. The time calibration was obtalned frum these peak locations by assuming a linear dependence of time-of-flight versus channel number. The neutron spectrum was then converted to an energy spectrum, defining the flight path to be the distance from the geometrical center of the target to the geometrical center of the liquid scintillator. Allowance was made for neutron absorption in the aluminum walls of the scattering chamber ( $\sim 3 \mathrm{~mm}$ thick) and the scintillator cell ( $1.5 \mathrm{~mm}$ thick) as well as the air along the flight path. The measured energy spectra from $\mathrm{d}+\mathrm{Be}$ at $0^{\circ}$ and $90^{\circ}$ are shown in $\mathrm{Fig}$. 4, with the error bars showing statistical uncertainties only. The data from $d+B e$ at all angles studied are shown as smouth cuives in Fig. 5. The curves for $7^{\circ}$ and $45^{\circ}$ do not extend below $5 \mathrm{MeV}$ as no runs were made at these angles with a $0.75 \mathrm{~m}$ flight path. Monitor uncertainties for the $0.75 \mathrm{~m}$ data were typically $8-15 \%$ as against $3-4 \%$ for the $3 \mathrm{~m}$ data. Accordingly, the relative normalization for the two data sets was derived from the total neutron yields for $7.5 \mathrm{MeV}<\mathrm{E}_{\mathrm{n}}<12.5 \mathrm{MeV}$, and the overall normalization defined by the monitor counts for the $3 \mathrm{~m}$ data.

The experimental uncertainties for these data come from three. sources. First, there are the statistical uncertainties indicated by the error bars in Figure 4. These are generally small. Second, there is a beam monitor uncertainty at each angle, which amounts to approximately $4 \%$ at all angles, except for $45^{\circ}$ where it is $6 \%$.

Finally, and most important, there are uncertainties due to the errors in the efficiency calculations. The resultant overall normalization uncertainty is estimated to be $\pm 15 \%$. Errors in the measured shape 
of the energy spectrum due to errors in the shape of the efficiency curve are difficult to assess, but are probably less than $10 \%$.

\subsection{Foil Activation Measurements}

The neutron yields. from the $\mathrm{d}+$ Be reaction at $\mathrm{E}_{\mathrm{d}}=39.9 \mathrm{MeV}$ were measured using the high intensity source described in section 2 . Rectangular foils, $50 \mathrm{~mm} \times 120 \mathrm{~mm}$, were mounted on a support in the shape of a circular arc $76.2 \mathrm{~mm}$ in radius, and the whole assembly located with the center of the arc at the center of the $d+B e$ interaction region, as shown schematically in Fig. 6. After exposure for 4 hours at a deuteron beam level of $20 \mu \mathrm{A}$ the foils were removed, allowed to cool for several days, and $6.3 \mathrm{~mm}$ diameter discs were punched from them in the pattern indicated in Fig. 6. The discs were weighed and the gamma activities listed in Table 1 were measured using a $\mathrm{Ge}(\mathrm{Li})$ detector whose efficiency was calibrated using a standard source.

To convert the measured activities to neutron yields the spectrumaveraged cross sections for the three reactions were computed as a function of scattering angle by folding the spectrum shapes as measured in the time-of-flight runs with the excitation functions shown in Figure 7. For energies $\lesssim 20 \mathrm{MeV}$ the available data ${ }^{14,15}$ ) for the ${ }^{59} \mathrm{Co}(n, 2 n)$ and ${ }^{93} \mathrm{Nb}(n, 2 n)$ reactions appear to be in reasonably good agreement, but considerable scatter of the experimental results is apparent for the ${ }^{58} \mathrm{Ni}(\mathrm{n}, \mathrm{p})$ case. ${ }^{16}$ ) Above $20 \mathrm{MeV}$ there are no data, so the excitation functions were extrapolated using the shapes calculated with the code THRESH. ${ }^{17}$ ) The overall uncertainties in the calculated spectrum averaged cross-sections were estimated to be $\pm 10 \%$ for the ${ }^{59} \mathrm{Co}(n, 2 n)$ and ${ }^{93} \mathrm{Nb}(n, 2 n)$ reactions, and $\pm 15 \%$ for the ${ }^{58} \mathrm{Ni}(n, p)$ reaction. In Fig. 8 we show the experimental values of neutron yield $\left(\mathrm{E}_{\mathrm{n}}>2 \mathrm{MeV}\right.$ ) versus angle obtained from the three activation foils, corrected for absorption in the tantalum end-plate. The time-of-flight data are also shown. The error bars indicate 
statistical uncertainties only. The solid line represents the mean of the TOF and activation results. The four sets of data are displaced from this curve by an average of $-10 \%$ (TOF), $+10 \%\left({ }^{59} \mathrm{Co}(n, 2 n)\right)$, $+1 \%\left({ }^{93} \mathrm{Nb}(n, 2 n)\right)$ and $-15 \%\left({ }^{58} \mathrm{Ni}(\mathrm{n}, \mathrm{p})\right)$, in reasonable agreement with the estimated uncertainties. In Table 2 the various sources of uncertainty are summarized for all sets of data.

In Table 3 the results of the four separate measurements of neutron yields $\left(E_{n}>2 \mathrm{MeV}\right)$ are 1 isted, together with the average values represented by the solid line in Fig. 8. Estimating probable errors for thcie average values from the s.nmplex error matrix implied by the information in Table 2 is nut practicable. The uncertaintios were therefore derived from the scatter of the experimental data points themselves, leading to error estimates of $\pm 5 \%$ at each angle, und an overall normalization uncertainty of $\pm 7 \%$.

Thick target neutron yields from the $d+$ Be reaction have previously been measured by Schweimer ${ }^{18}$ ) at $E_{d}=40 \mathrm{MeV}$ and $53.8 \mathrm{MeV}$, and by Meulders et a1. ${ }^{19}$ ) at $\mathrm{E}_{\mathrm{d}}=16 \mathrm{MeV}, 33 \mathrm{MeV}$ and $50 \mathrm{MeV}$. Schweimer's measurement of the neutron energy spectrum at $0^{\circ}$ extends down to a neutron energy of $11.5 \mathrm{MeV}$, and the shape is in good agreement with our results, however, his estimate of the ovorall yield is approximately 35\% lower. Meulders' data include enorgy spectra at a number of angles for neutron eirergios $\mathrm{E}_{\mathrm{n}}>3 \mathrm{MeV}$. No direct comparison with these data is possible due to the differing deuteron energies, but our data follow the same trends as regards spectral shapes, angular distributions and overall yields.

\section{Dosimetry for the $d+$ Be Neutron Source}

Both the neutron flux and encrgy spcctrum vary strongly with distance from the beam axis. Thus the dosimetry must provide a measure of both with a spatial resolution $\sim 1 \mathrm{~mm}$. The basis of the method is to assume that the neutron energy spectrum at any point on the sample is adequately represented by the neutron spectrum seen 
far from the target at some effective scattering angle $\left(\theta_{\text {eff }}\right)$. Then the neutron dose at a given point on the sample can be completely described by two numbers, the total neutron yield for $E_{n}>2 \mathrm{MeV}$ and the spectrum shape parameter $\theta$ eff.

The response of the nickel and cobalt foils in terms of these two parameters is obtained from the yield measurements described in the preceding section. From the activation measurements done in a well-defined geometry, the ratio of the cobalt and nickel activities at each scattering angle are obtained, and used to calculate the ratio of the spectrum averaged cross-sections, $\bar{\sigma}(\mathrm{CO}) / \bar{\sigma}(\mathrm{Ni})$, as a function of angle. The results are shown in Fig. 9. The solid line in Fig. 8, which is our best estimate of the total neutron yield, is used in conjunction with the same activation measurements to calculate the values of $\bar{\sigma}(\mathrm{Co})$ and $\bar{\sigma}(\mathrm{Ni})$ as function of scattering angle. These results (a) are given in Table 4, together with the values (b) previously estimated from the time-of-flight data and the published cross sections. (Strictly speaking the nickel values include a contribution from competing reactions such as ${ }^{60} \mathrm{Ni}(n, t){ }^{58} \mathrm{Co}$, however the correction-is probably $<5 \%$ and does not affect the present discussion). The dosimetry procedure which we use is to measure the activity induced on the cobalt and nickel foils at a given location, compute the ratio $\bar{\sigma}(\mathrm{Co}) / \bar{\sigma}(\mathrm{Ni})$ and then obtain $\theta_{\text {eff }}$ from Figure 9. Knowing $\theta$ eff the value of $\bar{\sigma}(\mathrm{Co})$ (or $\bar{\sigma}(\mathrm{Ni})$ ) can be obtained from Table 4 , and the total neutron fluence calculated.

An example of the method is illustrated in Fig. 1.0. The cobalt and nickel foils were in the form of $25 \mathrm{~mm}$ diameter discs, approximately $.05 \mathrm{~mm}$ thick, placed perpendicular to the beam axis at a distance of $10 \mathrm{~mm}$ from the center of the beryllium target. After an irradiation lasting $\sim 26 \mathrm{hrs}$, the pair of foils was removed and allowed to cool for several weeks. Discs $1.5 \mathrm{~mm}$ in diameter were then punched from the foils in the radial pattern shown on the insert of the upper part of Fig. 10. Each small disc was weighed, and the $810.5 \mathrm{keV}$ $\gamma$-activity measured with a $\mathrm{Ge}(\mathrm{Li})$ detector. From these data the 
location of the center of the neutron spot (i.e. the maximum activity) was estimated, and the activity of each disc plotted against its distance $\mathbf{r}$ from this center, as shown in Fig. 10. There is an implicit assumption in this procedure that the neutron intensity countours are circular, which appears to be well justified by the small scatter of the data points in these plots. From the data in the upper part of Fig. 10 the two dose parameters, $\theta_{\text {eff }}$ and neutron yield were calculated and plotted as a function of $r$ as shown in the lower part of the figure. The neutron spot is seen to have a ruughly gaussian profile, with a full width at half maximum of $8.5 \mathrm{~mm}$, and a maximum of $\sim 2 \times 10^{17} \mathrm{n} / \mathrm{cm}^{2}$, corresponding to a average flux $\sim 2.1 \times 10^{12} \mathrm{n} / \mathrm{cm}^{2} / \mathrm{sec}$ during the irradiation.

The overal1 uncertainty in the neutron fluence is estimated to be $\pm 10 \%$ due largely to the $7 \%$ uncertainty of the yield measurements used to calibrate the activation foils. The uncertainty in the definition of spectral shape is difficult to quantify, but in terms of the effective scattering angle it amounts to $\pm 2^{\circ}$, as indicated in Fig. 10.

Although we can give no rigorous justification of this procedure, a plausible argument in support of the basic assumption can be made by noting that neutron energy spectrà shown in Fig. 5 are composed of two components, a broad peak centered near $E_{n}=16 \mathrm{MeV}$ and an underlying background with a roughly exponential energy dependence. The intensity of the broad peak decreases rapidly with angle while that of the underlying background varies much more slowly. We may express the yield $\phi$ at an angle $A$ as

$$
\phi(\theta, E)=g_{p}(\theta) f_{p}(E)+g_{b}(\theta) f_{b}(E)
$$

where 
$f_{p}(E)$ represents the shape of the broad peak, $f_{b}(E)$ represents the shape of the underlying background, and $g(\theta)$ are the corresponding angular distributions.

When a sample is placed close to the source, so that the beam spot subtends a significant angle at the sample, the spectrum seen by the sample $\psi(E)$ may be represented by an integral of $\phi(\theta, E)$ over the appropriate angular range, i.e.

$$
\psi(E)=\int_{\theta_{\min }}^{\theta_{\max } x(\theta) \phi(\theta, E) d \phi}
$$

where $x(\theta)$ depends upon the beam intensity profile, divergence, etc.

Substituting (1) into (2) we obtain

$$
\begin{aligned}
\psi(E) & =f_{p}(E) \int_{\theta_{\min }}^{\theta} \max _{d \theta} x(\theta) g_{p}(\theta)+f_{b}(E) \int_{\theta_{\min }}^{\theta} \max d \theta x(\theta) g_{b}(\theta) \\
& =a_{p} f_{p}(E)+a_{b} f_{b}(E) .
\end{aligned}
$$

This spectrum has the same form as the spectrum $\phi\left(\theta_{\text {eff }}, E\right)$ at an angle ${ }^{\theta}$ eff from a point source, where

$$
a_{p} / a_{b}=g_{p}\left(\theta_{\text {eff }}\right) / g_{b}\left(\theta_{\text {eff }}\right)
$$

Thus, provided that the functions $x(\theta), g_{p}(\theta)$ and $g_{b}(\theta)$ are reasonably well behaved, the neutron spectrum seen by a sample placed close to the source can be characterized by the spectrum measured far from the source at some angle $\theta_{\text {eff }}$. 
Given the assumption represented by Eq. (1), i.e. that the spectrum at any angle is the sum of two components whose energy dependence is independent of angle, the above argument is still not rigorous because the finite thickness of the source has been ignored. This effect cannot be evaluated without a knowledge of the thintarget neutron yields for the ${ }^{9} \mathrm{Be}(\mathrm{d}, \mathrm{n})$ reaction over the full deuteron energy range of 0 to $40 \mathrm{MeV}$.

\section{Neutron Yields from the $d+$ Li Reaction}

In the recent ORNL proposal ${ }^{8}$ ) for an intense neutron generator based on the $d+L i$ reaction, results were reported for the thick target neutron yield from $40 \mathrm{MeV}$ deuteron bombardment of lithium. These data are in disagreement, by a factor of two, with other preliminary results reported in the similar BNL proposal. ${ }^{7}$ ) we have repeated these measurements using the time-of-flight apparatus described previously and the results, shown in Fig. 11, are consistent with the earlier ORNL data. The total neutron yields for $E_{n}>2 \mathrm{MeV}$ from the present work, which are given in Table 5, have sources of error which are similar to those listed in Table 2 for the beryllium results. From the beryllium data we see that the time-of-flight results are $10 \%$ lower than the average values for the total yields, accordingly the lithium data should be renormalized upwards by this amount, as shown in the final column of Table 5. The errors quoted in this column reflect not only statistical errors, but also those due to uncertainties in the shape of the detector efficiency curves.

The results indicate a slightly higher yield for the d + Li reaction as compared to the $d+$ Be reaction as might be expected from the systematics noted by Schweimer ${ }^{18}$ ). The forward angle spectra also show a reduced contribution at the lower neutron energies. However, the overall similarity of the spectra from the two reactions suggest that $d+B e$ sources will be useful in examining the neutronics of the proposed $d+L i$ sources, and that the dosimetry techniques described here will be applicable to such devices. 


\section{$\underline{\text { References }}$}

1) D. Steiner, Nucl. Sci. Eng. 58, 107 (1975).

"Report to the APS by the Study Group on Physics Problems Relating to Energy Technologies: Radiation Effects on Materials," Rev. Mod. Phys. 47, Supp1. No. 3 (1975).

2) R. Booth and H. H. Barshal1, Nucl. Inst. and Meth. 99, 1 (1972).

3) L. H. Jenkins, T. S. Noggle, R. E. Reed, M. J. Saltmarsh and G. T. Smith, App1. Phys. Lett. 26, 426 (1975).

4) J. B. Roberto, J. Narayan and M. J. Saltmarsh, Proceedings of the International Conference on Radiation Effects and Tritium Technology for Fusion Reactors, Gatlinburg, Tennessee, CONF-750989, 2, 159 (1976).

5) J. C. Davis, J. D. Anderson, R. Booth, C. M. Logan, and J. E. Osher, "Proceedings of the International Conference on Radiation Test Facilities for the CTR Surface and Materials Program," Argonne National Laboratory, ANL/CTR-75-4, 183 (1975).

6) Dale D. Armstrong, C. Robert Emigh, Karl L. Meier, Earl A. Meyer and J. David Schneider, p. 261 of Ref. 5.

7) P. Grand (Ed.), "Accelerator-Based Neutron Generator," BNL-20159 (1975).

8) M. J. Saltmarsh and R. E. Worsham (Ed.), "INGRTD = An Intense Neutron Generator for Radiation-Induced Damage Studies in the CTR Materials Progran," ORNL-TM-5233 (1976). 
9) "CTR Materials Irradiation Testing Facility (CMIT) Proposal," Hanford Engineering and Development Laboratory (1975).

10) "A Proposal for a High Intensity Neutron Source," Lawrence Livermore Laboratory, LLL-Prop 137 (1976).

11) Manufactured by Nuclear Enterprises, Inc., 935 Terminal Way, San Carlos, California 94070.

12) V. V. Verbinski, W. R. Burmus, T. A. Love, W. Zobel, N. W. Hill and R. Textor, Nucl. Inst, and Meth. 65, 8 (1968).

13) R. E. Textor and V. V. Verbinski, ORNL-4160 (1968).

14) ENDF-B-IV, MAT-1199, BNL 1754]. (ENDF-201) (1975).

15) A. Paulsen and R. Widera, Z. Physik, 238, 23 (1970).

16) ENDP-B-IV, MAT-1190, BNL 17541 (ENDF-201) (1975).

17) S. Pearlstein, J. Nucl. Eng. 27, 81 (1973).

18) G. W. Schweimer, Nucl. Phys. Al00, 537 (1967).

19) J. P. Meulders, P. Leleux, P. 6. Marq, and C. Pirart, Phys. Med. Biol. 20, 235 (1975). 


\section{TABLE 1}

Reactions used for activation measurements.

\begin{tabular}{lcccc}
\hline Foil & Reaction & $\begin{array}{c}\text { Q-value } \\
(\mathrm{MeV})\end{array}$ & $\begin{array}{c}{ }^{\tau} 1 / 2 \\
(\text { days })\end{array}$ & $\begin{array}{c}\mathrm{E}_{\gamma} \\
(\mathrm{keV})\end{array}$ \\
\hline $\mathrm{Ni} \mathrm{(nat)*} \cdot{ }^{58} \mathrm{Ni}(\mathrm{n}, \mathrm{p}){ }^{58} \mathrm{Co}$ & 0.39 & 71.3 & 810.5 \\
$\mathrm{Co}$ & ${ }^{59} \mathrm{Co}(\mathrm{n}, 2 \mathrm{n}){ }^{58} \mathrm{Co}$ & -10.47 & 71.3 & 810.5 \\
$\mathrm{Nb}$ & ${ }^{93} \mathrm{Nb}(\mathrm{n}, 2 \mathrm{n}){ }^{92 \mathrm{~m}_{\mathrm{Nb}}}$ & -8.95 & 10.16 & 934 \\
\hline
\end{tabular}

*Contributions to the ${ }^{58}$ Co yield from reactions in other nickel isotopes such as ${ }^{60} \mathrm{Ni}(n, t)$ were assumed to be negligible. 
TABLE 2

Summary of Uncerzainties in total neutron yield data.

\begin{tabular}{|c|c|c|c|}
\hline Data Source & Source of Uncertairty & Magnitude & Comments \\
\hline \multirow[t]{4}{*}{ TOF } & Counting statistics & Small & Indicated in Fig. 4 \\
\hline & Monitor statistics & $4 \%-6 \%$ & Indicated in Fig. 8 \\
\hline & Monitor calibration & $3 \%$ & \\
\hline & Detector efficiency & $15 \%$ (estimated) & $\begin{array}{l}\text { Considerable correlation } \\
\text { between different } \\
\text { angles }\end{array}$ \\
\hline \multirow[t]{4}{*}{${ }^{58} \mathrm{~N} \dot{\mathrm{i}}(\mathrm{n}, \mathrm{p})$} & Coun=ing statistics & $1 \%-5 \%$ & Indjcated in Fig. 8 \\
\hline & $\begin{array}{l}\text { Ge(Ii) detector } \\
\text { efficiency }\end{array}$ & $5 \%$ & $\begin{array}{l}\text { Same far all activation } \\
\text { deta }\end{array}$ \\
\hline & Cross sections & $15 \%$ (estimated) & Cansiderable correlation \\
\hline & TOF Spectral shapes & & between angles \\
\hline \multirow[t]{3}{*}{${ }^{59} \operatorname{Co}(n, 2 n)$} & Coumting statistics & $1-8 \%$ & \multirow{3}{*}{ As $\operatorname{Eor}{ }^{58} \mathrm{Ni}(\mathrm{n}, \mathrm{p})$} \\
\hline & Detec $=c r$ efficiency & $5 \%$ & \\
\hline & Cross-sections & $10 \%$ (estimated) & \\
\hline
\end{tabular}


TABLE 2 (cont.)

\begin{tabular}{llll}
\hline Data Source & Source of Uncertainty & Magnitude & Comments \\
\hline${ }^{93}{ }^{\mathrm{Nb}(\mathrm{n}, 2 \mathrm{n})}$ & Counting statistics & $1-8 \%$ \\
& Detector efficiency & $5 \%$ \\
& Cross-sections \\
& TOF spectral shapes
\end{tabular}$\quad \begin{aligned} & \\
& \end{aligned}$


TABLE 3

Thick target reutron yi $\equiv 1 \mathrm{ds}\left(\mathrm{E}_{\mathrm{n}}>2 \mathrm{MeV}\right)$ from $\mathrm{d}+\mathrm{Be}, \mathrm{E}_{\mathrm{d}}=40 \mathrm{MeV}$. Units are $10^{10}$ neutrons $/ \mu \mathrm{C} / \mathrm{sr}$.

\begin{tabular}{|c|c|c|c|c|c|}
\hline \multirow{3}{*}{$\begin{array}{l}\text { Scattering angle } \\
\text { (degrees) }\end{array}$} & \multicolumn{4}{|c|}{ Neutron Yields } & \\
\hline & \multirow[t]{2}{*}{ TOF data } & \multicolumn{3}{|c|}{ Activation data } & \multirow[t]{2}{*}{ Average* } \\
\hline & & ${ }^{59} \operatorname{Co}(n, 2 n)$ & ${ }^{58} \mathrm{Ni}(\mathrm{n}, \mathrm{p})$ & ${ }^{93} \mathrm{Nb}(2,2 n)$ & \\
\hline 0 & $33.6 \pm 1.3$ & $38.7 \pm 0.4$ & $30.9 \pm 0.3$ & $35.7 \pm 0.4$ & $36.0 . \pm 1.8$ \\
\hline 5 & & $33.7 \pm 0.4$ & $24.8 \pm 0.3$ & $29.9 \pm 0.3$ & $30.0 \pm 1.5$ \\
\hline 7 & $25.1 \pm 1.3$ & & & & $26.6 \pm 1.3$ \\
\hline 10 & & $26.0 \pm 0.2$ & \pm 0.2 & $23.1 \pm 0.2$ & $22.2 \pm 1.1$ \\
\hline 15 & $13.2 \pm 0.5$ & $18.5 \pm C .3$ & & & $15.4 \pm 0.8$ \\
\hline 20 & & $13.4 \pm 0.2$ & $9.51 \pm 0.13$ & $11.6 \pm 0.2$ & $11.7 \pm 0.6$ \\
\hline 30 & $6.8 \pm 0.2$ & $9.26 \pm 0.17$ & $6.59 \pm 0.11$ & $8.19 \pm 0.2$ & $8.1 \pm 0.4$ \\
\hline 40 & & $7.29 \pm 0.23$ & $5.12 \pm 0.12$ & $6.65 \pm 0.2$ & $5.9 \pm 0.3$ \\
\hline 45 & $4.2 \pm 0.25$ & & & & $5.05 \pm 0.25$ \\
\hline 50 & & $4.86 \pm 0.15$ & $3.74 \pm 0.06$ & $4.36 \pm 0.16$ & $4.30 \pm 0.22$ \\
\hline 60 & $2.77 \pm 0.1$ & $3.30 \div 0.13$ & $2.79 \pm .07$ & $3.34 \pm 0.11$ & $3.14 \pm 0.16$ \\
\hline 70 & & $2.21 \pm 0.16$ & $2.10 \pm .08$ & $2.31 \pm 0.14$ & $2.30 \pm 0.12$ \\
\hline 80 & & $1.56=0.16$ & $1.68 \pm .06$ & $1.39 \pm 0.08$ & $1.67 \pm 0.08$ \\
\hline 90 & $1.26 \pm .04$ & & & & $1.21 \pm 0.06$ \\
\hline Scale uncertainty & $\pm 15 \%$ & $\pm 10 \%$ & $\pm 15 \%$ & $\pm 10 \%$ & $\pm 7 \%$ \\
\hline
\end{tabular}

${ }^{*}$ Corresponds to solid 1 ine in Figure 8. 
TABLE 4

Estimates of the spectrum-averaged cross-sections (in mb) for various reactions as a function of scattering angle. Values 1 abeled (a) are used for dosimetry (see text). Values labeled (b) were calculated from time-of-flight data and available cross-section data.

\begin{tabular}{|c|c|c|c|c|c|c|}
\hline \multirow[b]{3}{*}{$\begin{array}{c}\theta \\
\text { (degrees) } \\
\end{array}$} & \multicolumn{2}{|c|}{${ }^{58} \mathrm{Ni}(\mathrm{n}, \mathrm{p})^{58} \mathrm{Co}$} & \multicolumn{2}{|c|}{${ }^{59} \mathrm{Co}(n, 2 n){ }^{58} \mathrm{Co}$} & \multicolumn{2}{|c|}{${ }^{93} \mathrm{Nb}(n, 2 n)^{92 \mathrm{~m}} \mathrm{Nb}$} \\
\hline & \multicolumn{2}{|c|}{$\bar{\sigma}(\mathrm{Ni})$} & \multicolumn{2}{|c|}{$\bar{\sigma}(\mathrm{Co})$} & \multicolumn{2}{|c|}{$\bar{\sigma}(\mathrm{Nb})$} \\
\hline & (a) & (b) & (a) & (b) & (a) & (b) \\
\hline 0 & 270 & $316 \pm 47$ & 424 & $394 \pm 39$ & 205 & $210 \pm 20$ \\
\hline 5 & 270 & & 400 & & 195 & \\
\hline 7 & 270 & $330 \pm 50$ & 383 & $332 \pm 33$ & 187 & $183 \pm 18$ \\
\hline 10 & 272 & & 348 & & 174 & \\
\hline 15 & 278 & $341 \pm 51$ & 300 & $257 \pm 26$ & 149 & $146 \pm 15$ \\
\hline 20 & 283 & & 260 & & 131 & \\
\hline 30 & 298 & $369 \pm 55$ & 212 & $186 \pm 19$ & 116 & $117 \pm 12$ \\
\hline 40 & 313 & . & 175 & & 103 & \\
\hline 45 & 320 & $386 \pm 58$ & 161 & $168 \pm 17$ & 98 & $113 \pm 11$ \\
\hline 50 & 329 & & 148 & & 93 & \\
\hline 60 & 343 & $375 \pm 56$ & 124 & $116 \pm 12$ & 83 & $83 \pm 8$ \\
\hline 70 & 361 & & 101 & & 74 & \\
\hline 80 & 380 & & 87 & & 66 & \\
\hline 90 & 400 & $368 \pm 55$ & 72 & $76 \pm 8$ & 58 & $60 \pm 6$ \\
\hline
\end{tabular}


TABLE 5

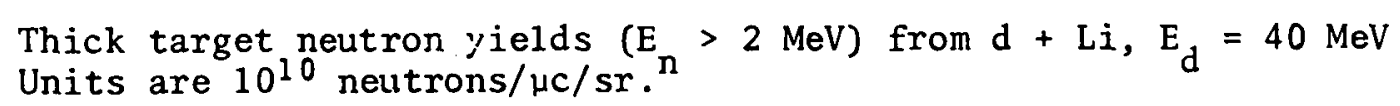

Scattering angle (degrees)

\begin{tabular}{|c|c|c|}
\hline \multirow[b]{2}{*}{ (degrees) } & \\
\hline & TOF data ${ }^{a}$ & Renormalized \\
\hline $0^{\circ}$ & $36.7 \pm 1.8$ & $40.9 \pm 2.9$ \\
\hline $7^{\circ}$ & $25.3 \pm 1.3$ & $38.2 \pm 2.0$ \\
\hline $15^{\circ}$ & $11.6 \pm 0.4$ & $13.0 \pm 0.9$ \\
\hline $30^{\circ}$ & $6.28 \pm 0.25$ & $6.99 \pm 0.50$ \\
\hline $45^{\circ}$ & $3.73 \pm 0.17$ & $4.15 \pm 0.30$ \\
\hline $60^{\circ}$ & $2.48 \pm 0.09$ & $2.76 \pm 0.19$ \\
\hline $90^{\circ}$ & $1.43 \pm 0.05$ & $1.59 \pm 0.11$ \\
\hline Scale uncertainty & $\pm 15 \%$ & $\pm 7 \%$ \\
\hline
\end{tabular}

Neutron yield

\footnotetext{
'Statistical exrors only

$\mathrm{b}_{\text {See }}$ section 5 .
} 
ORNL - DWG $76-13767 R$

TO CURRENT

MONITORS

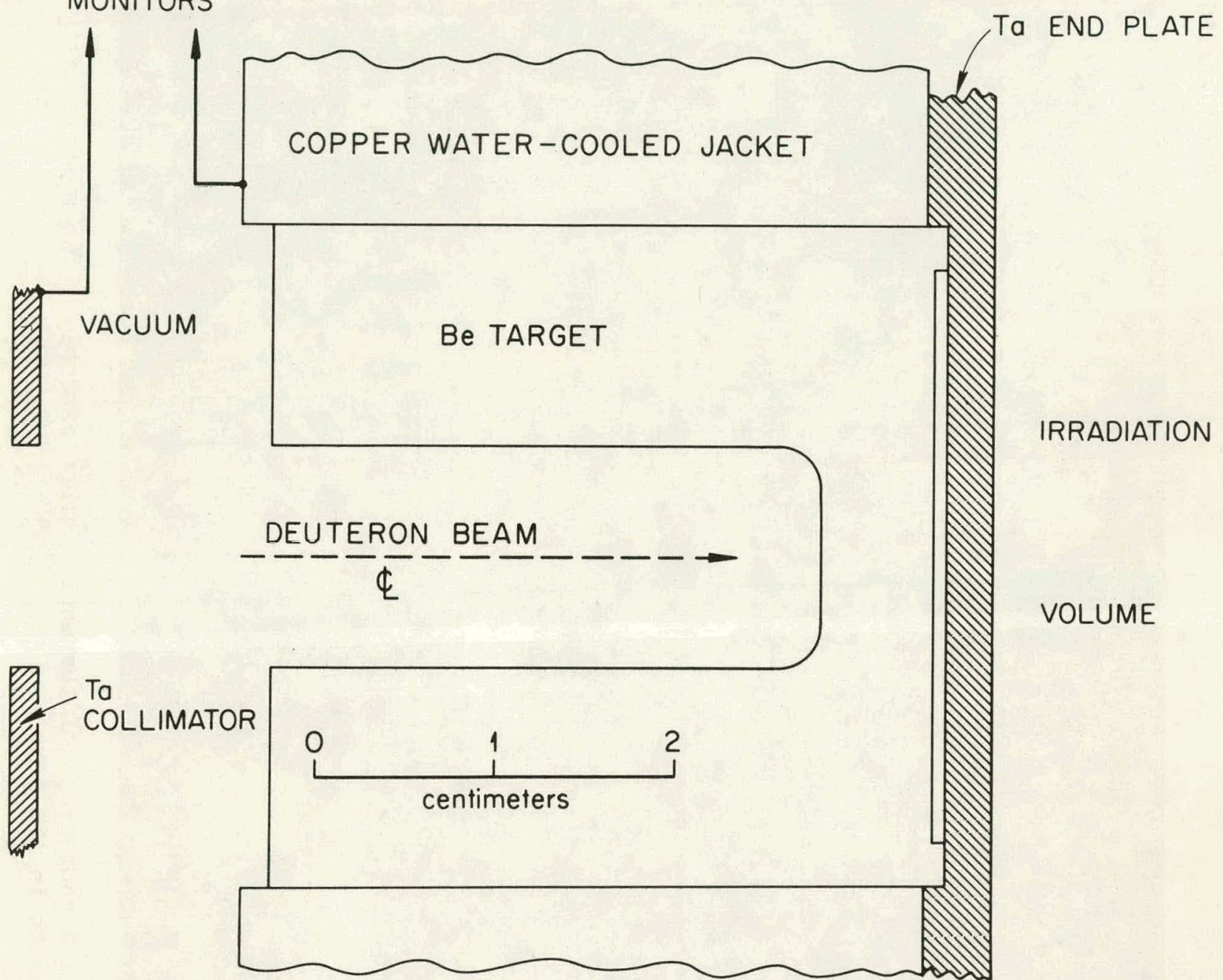

Fig. 1. A schematic of the water-cooled beryllium target. Samples to be irradiated are placed within the irradiation volume immediately downstream of the tantalum end-plate. 


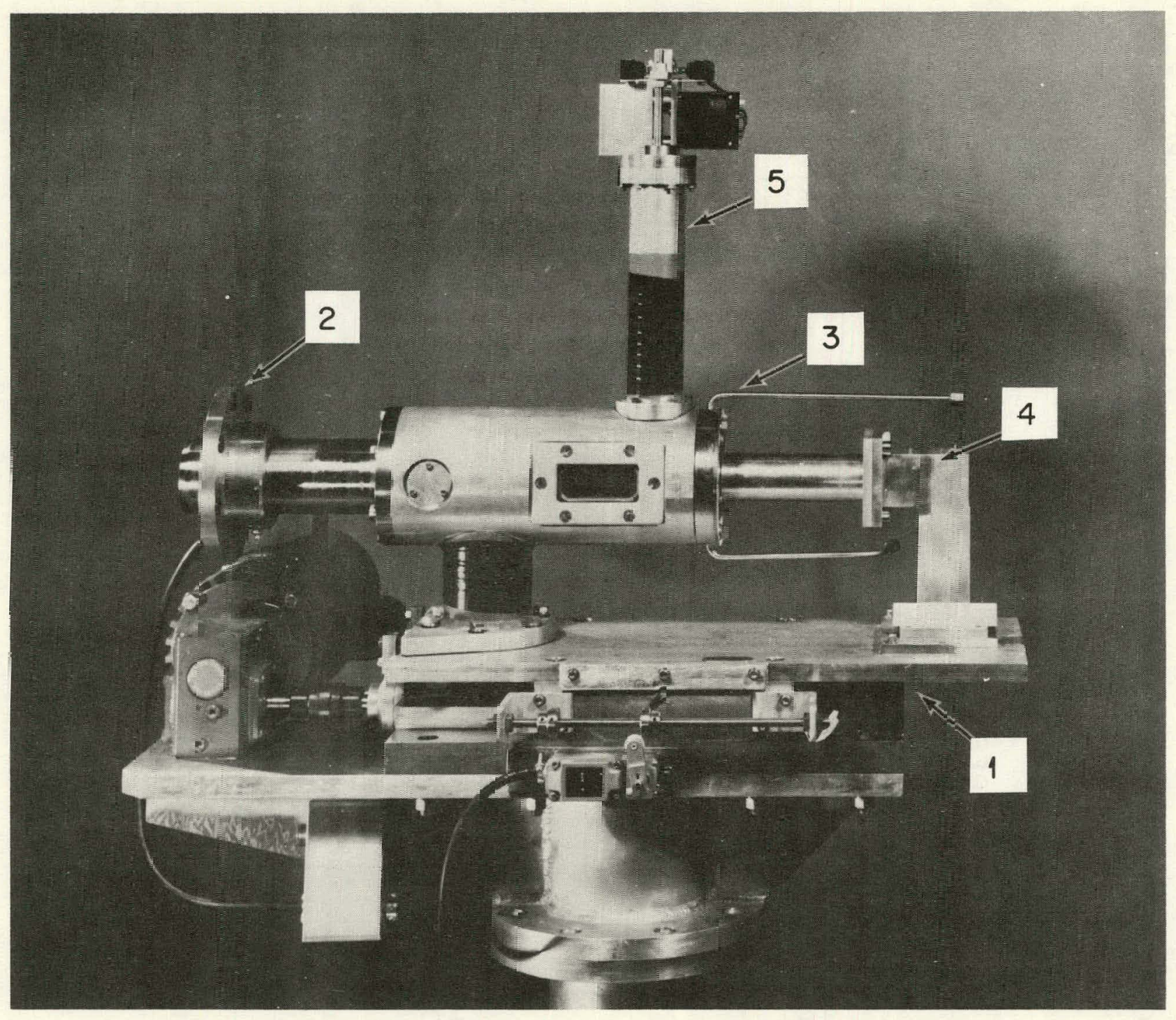

F-g. 2. A photograph of the whole target assembly. The numbers are referred $t=$ in the text. 
ORNL-DWG $76-13772$

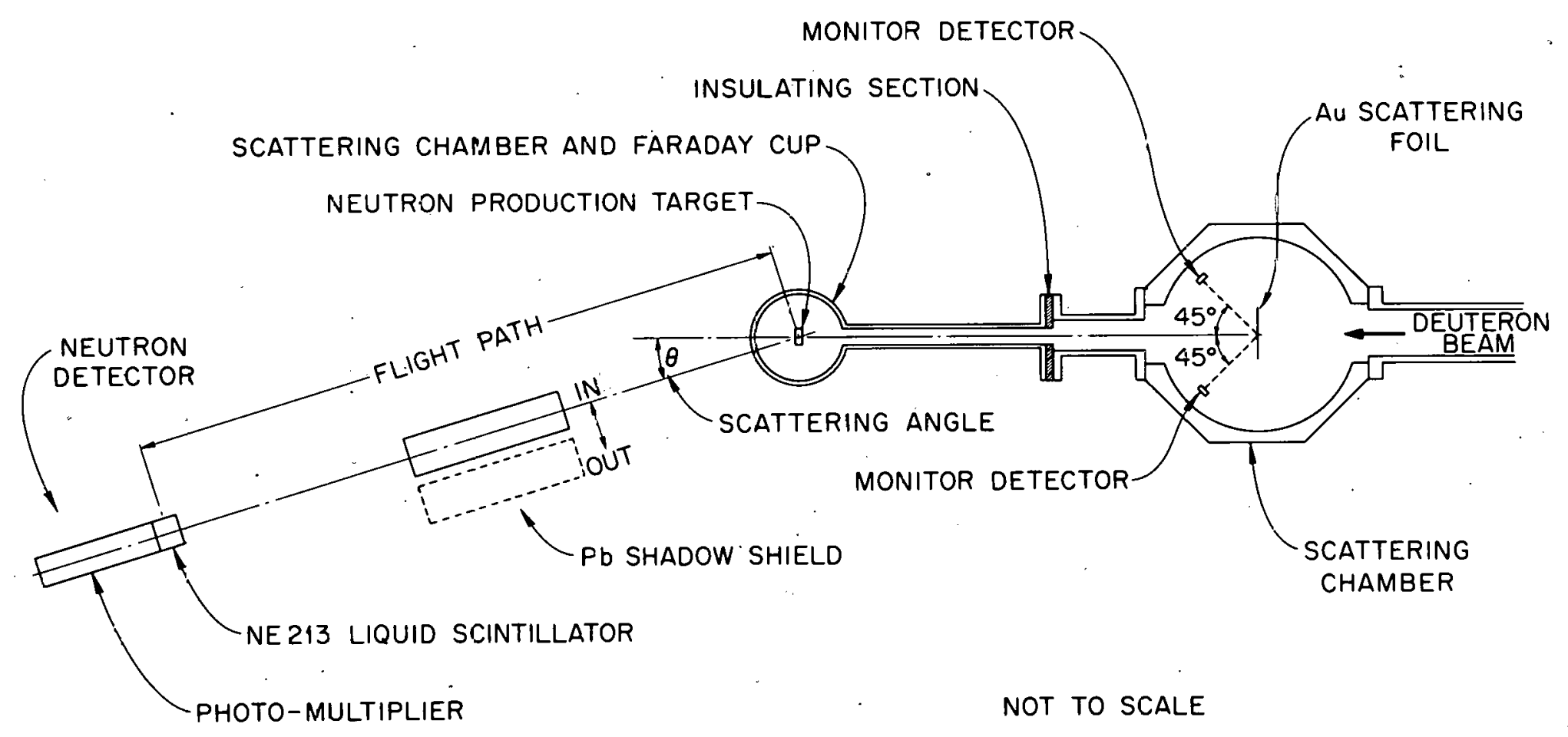

Fig. 3. The lay-out of the time-of-flight apparatus. 


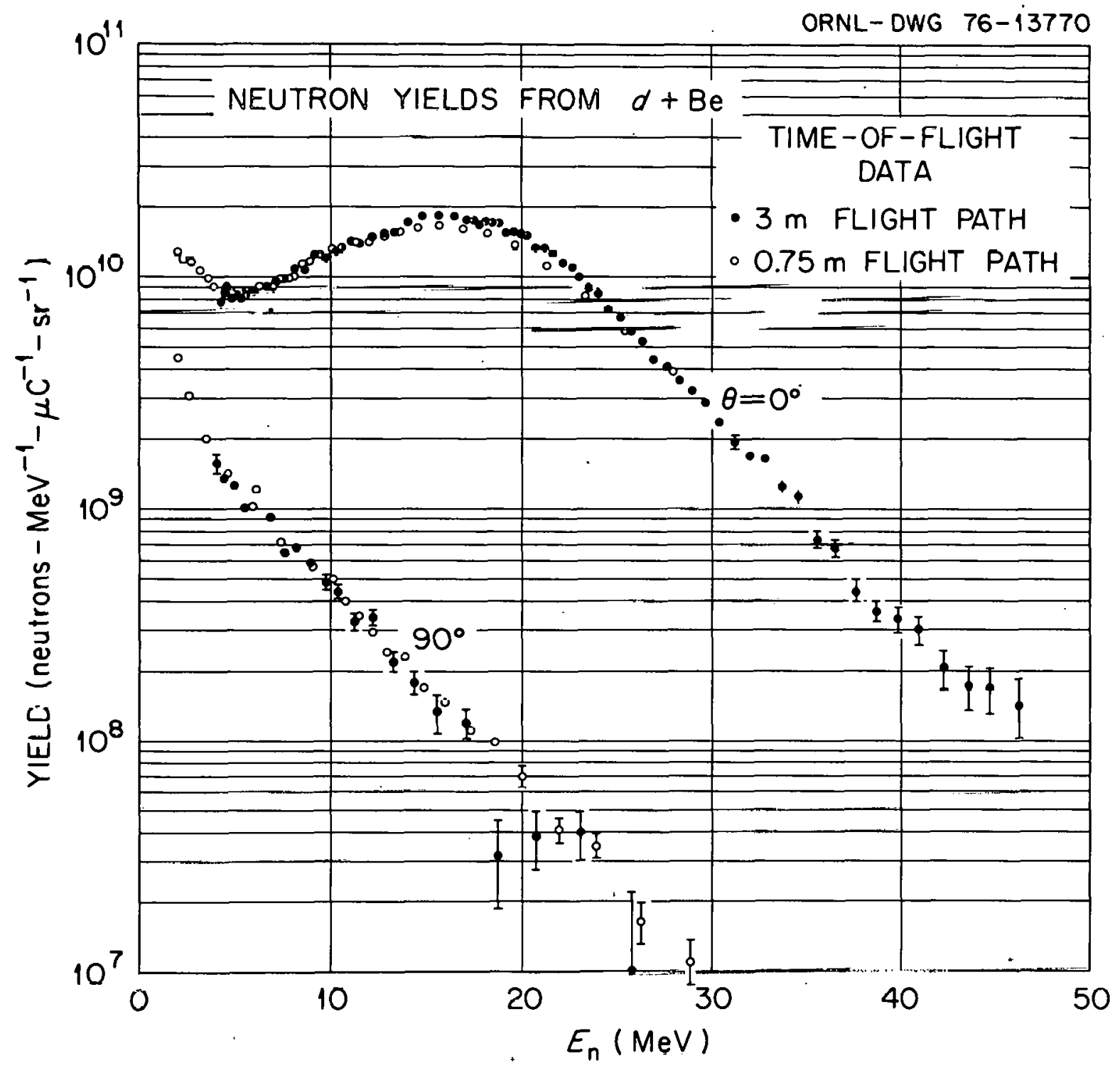

Fig. 4. Time-uf-flight data from $40 \mathrm{MeV}$ deuterons on a thick Be target, showing representative error bars. The $0.75 \mathrm{~m}$ data (open circles) have been normalized to the $3 \mathrm{~m}$ data in the energy ranges $7.5 \mathrm{MeV}<\mathrm{E}_{1}<12.5 \mathrm{MeV}$. The system resolution (3m data) varies from $\approx 200 \mathrm{keV}$ at $\mathrm{E}_{\mathrm{n}}=5 \mathrm{MeV}$ to $\approx 6 \mathrm{MeV}$ at $\mathrm{E}_{\mathrm{n}}=40 \mathrm{MeV}$. 


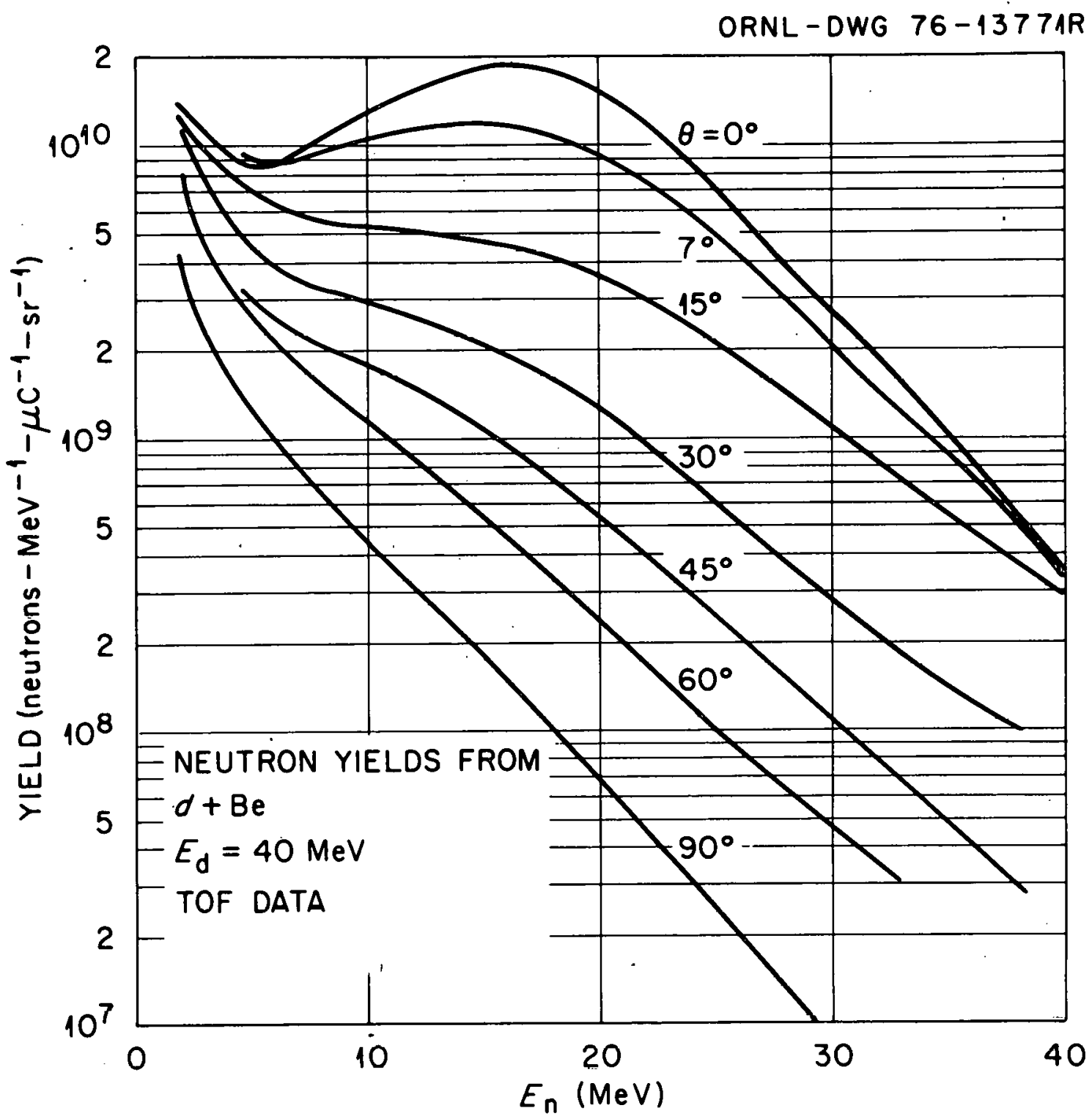

Fig. 5. Time-of-flight data obtained by drawing smooth curves through the results typified by those in Fig. 4. 
ORNL- DWG 76-14018

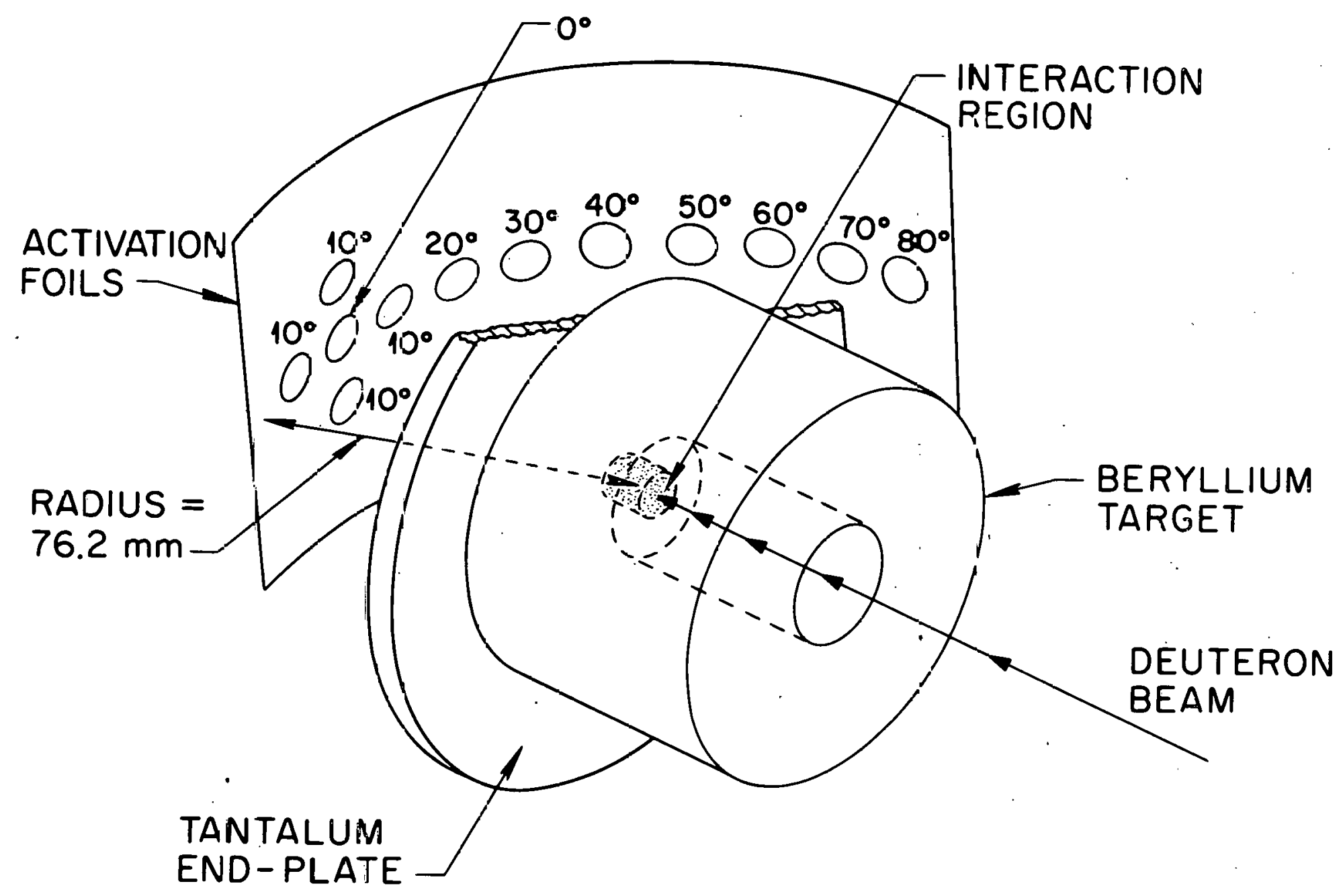

Fig. 6. The experimental arrangement used for the activation measurements in a well-defined geometry. The dinensicns of the interaction region were length $6 \mathrm{~mm}$, diameter $<5 \mathrm{~mm}$. 


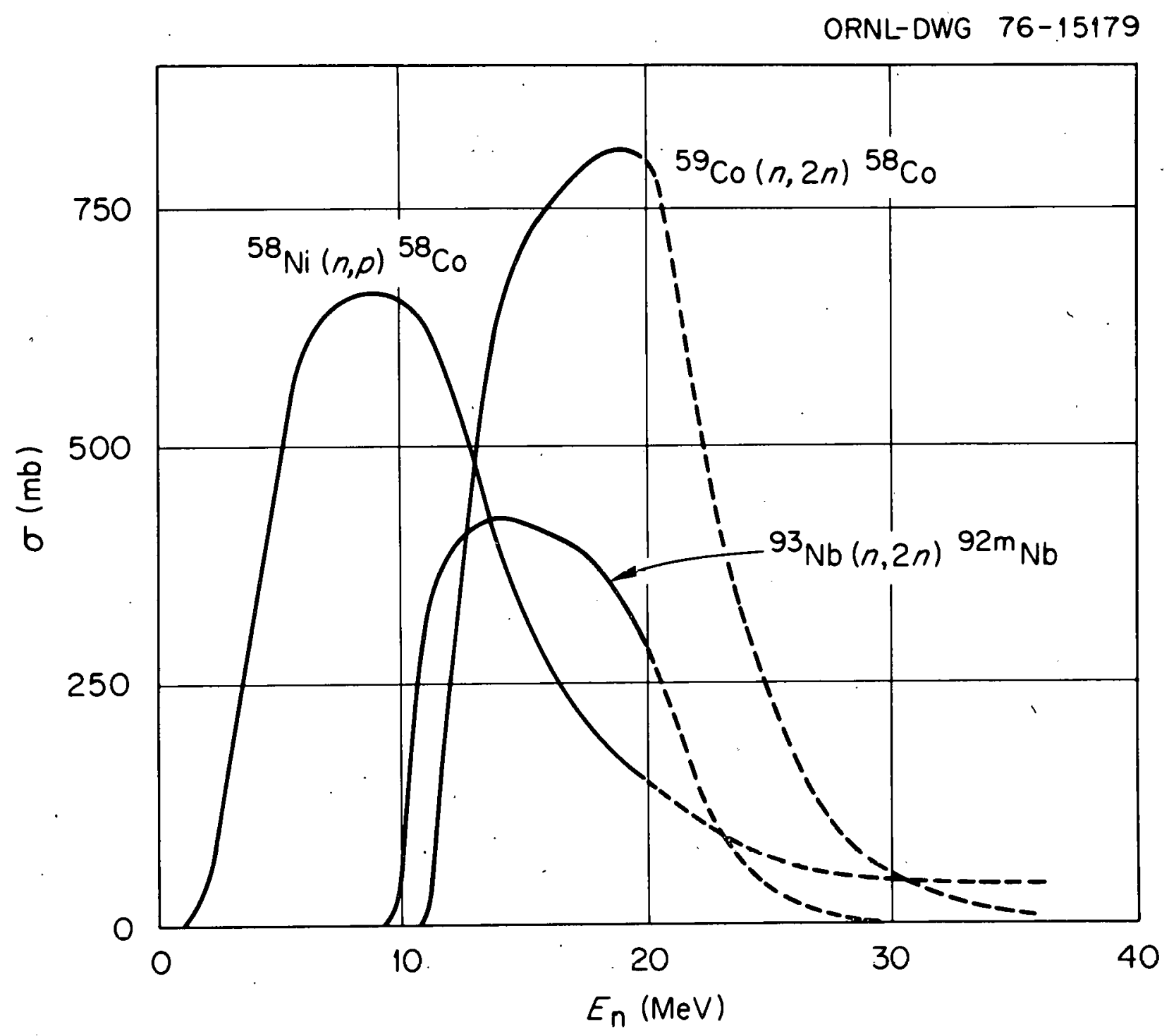

Fig. 7. Excitation functions used to calculate spectrum averaged cross sections. The solid lines represent the energy regions for which data ${ }^{14}, 15,16$ ) were available ; the dotted portions were extrapolations derived from Ref. 17. 
OPNL-DWG 76-13768R

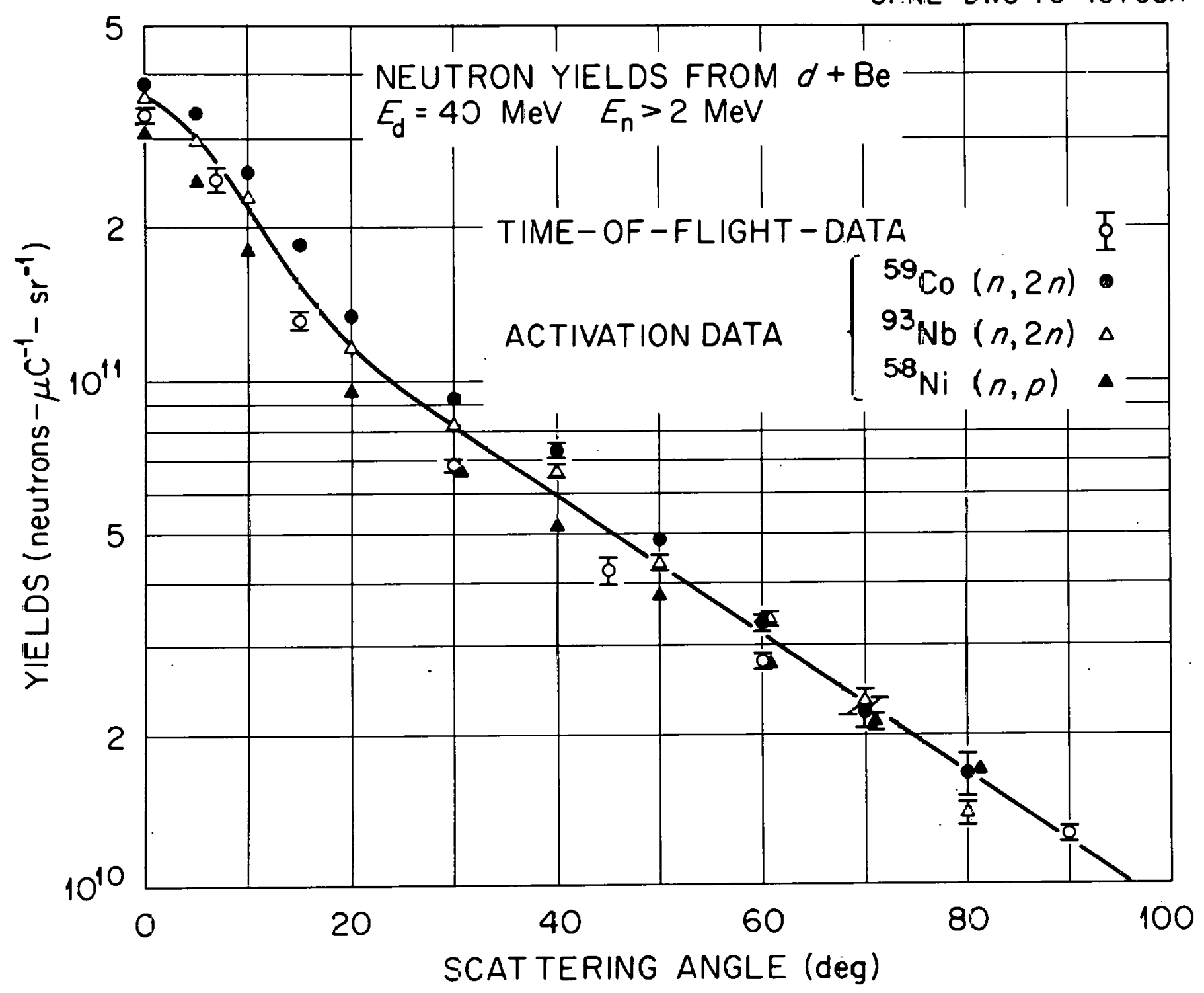

Fig. 8. Experimentzl values of neutron yield abtained in the present work for $40 \mathrm{MeV}$ deuterons on thick beryllium targets. 


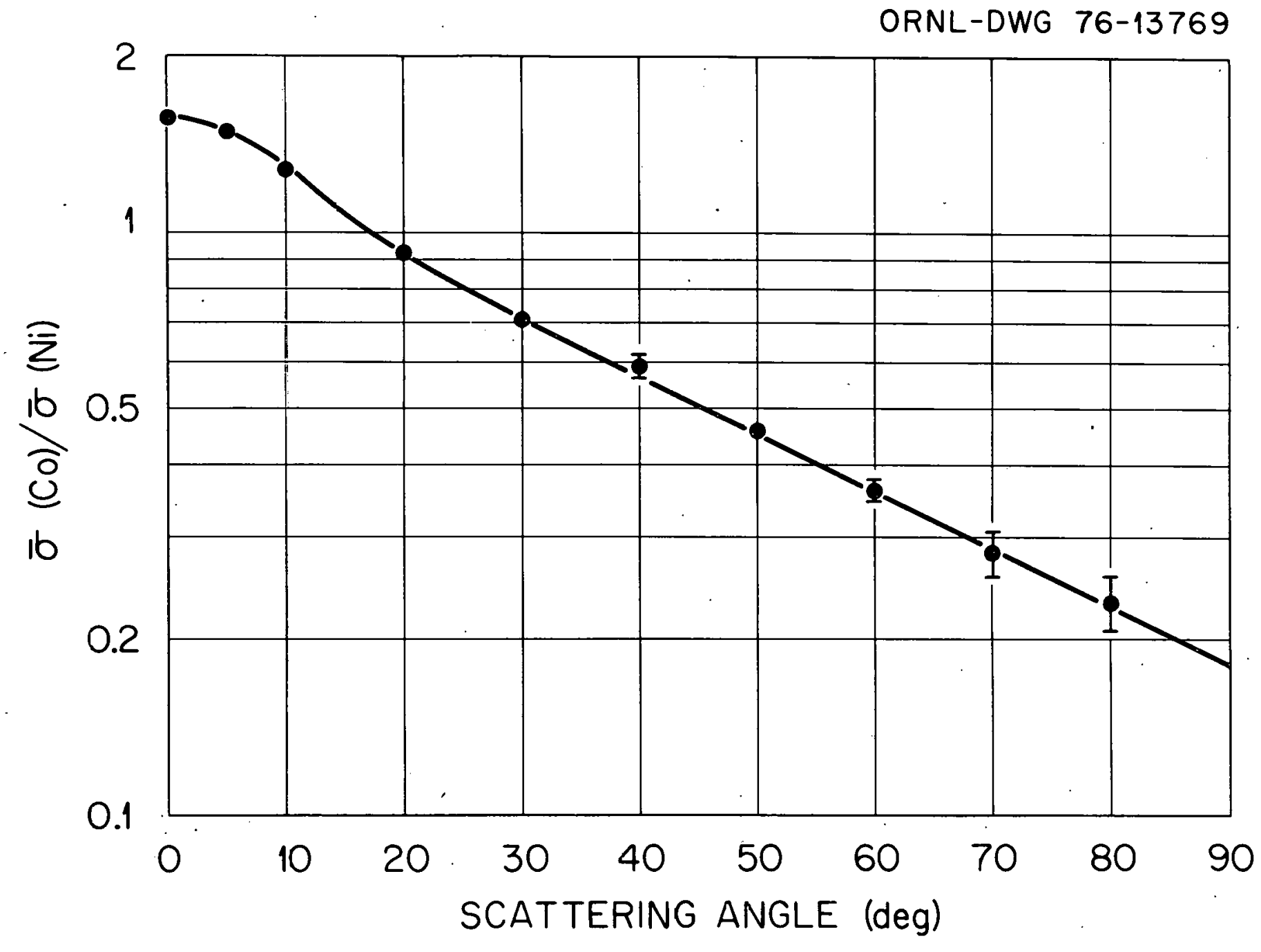

Experimental Dependence of $\frac{\bar{\sigma}(\mathrm{Co})}{\bar{\sigma}(\mathrm{Ni})}$ vs Angle

Fig. 9. Experimental dependence of $\bar{\sigma}(\mathrm{Co}) / \bar{\sigma}(\mathrm{Ni})$ as a function of angle for neutrons emitted from a thick target bombirded with $40 \mathrm{MeV}$ deuterons. 


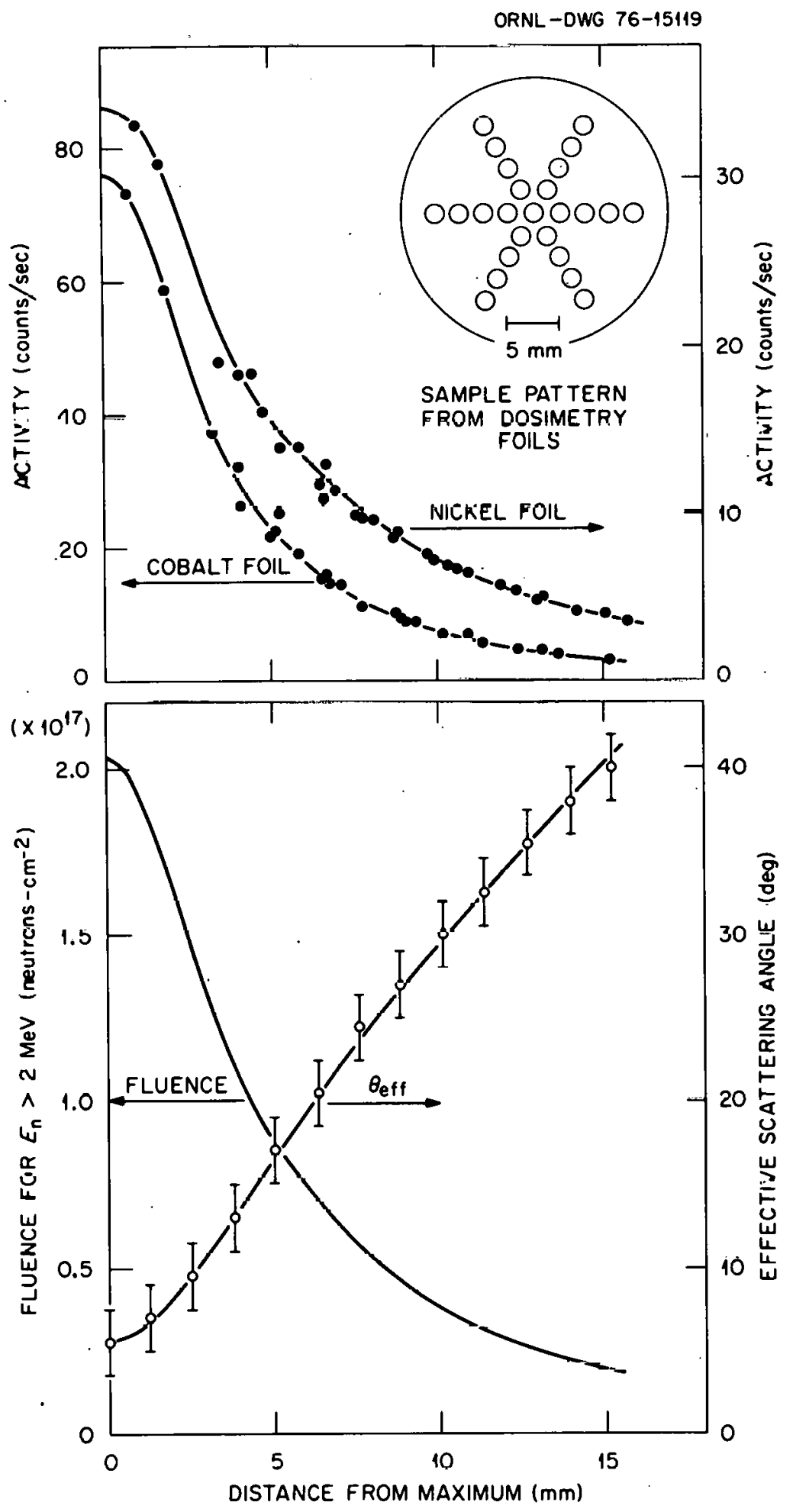

Fig. 10. Dosimetry method used for $d+$ Be neutron source. The upper graphs show the distribution of ${ }^{58}$ Co activity for the cobalt and nickel dosimetry foils. The lower plots show the spatial dependence of $\theta$ eff and neutron yield inferred from these measurements (see section 4). 


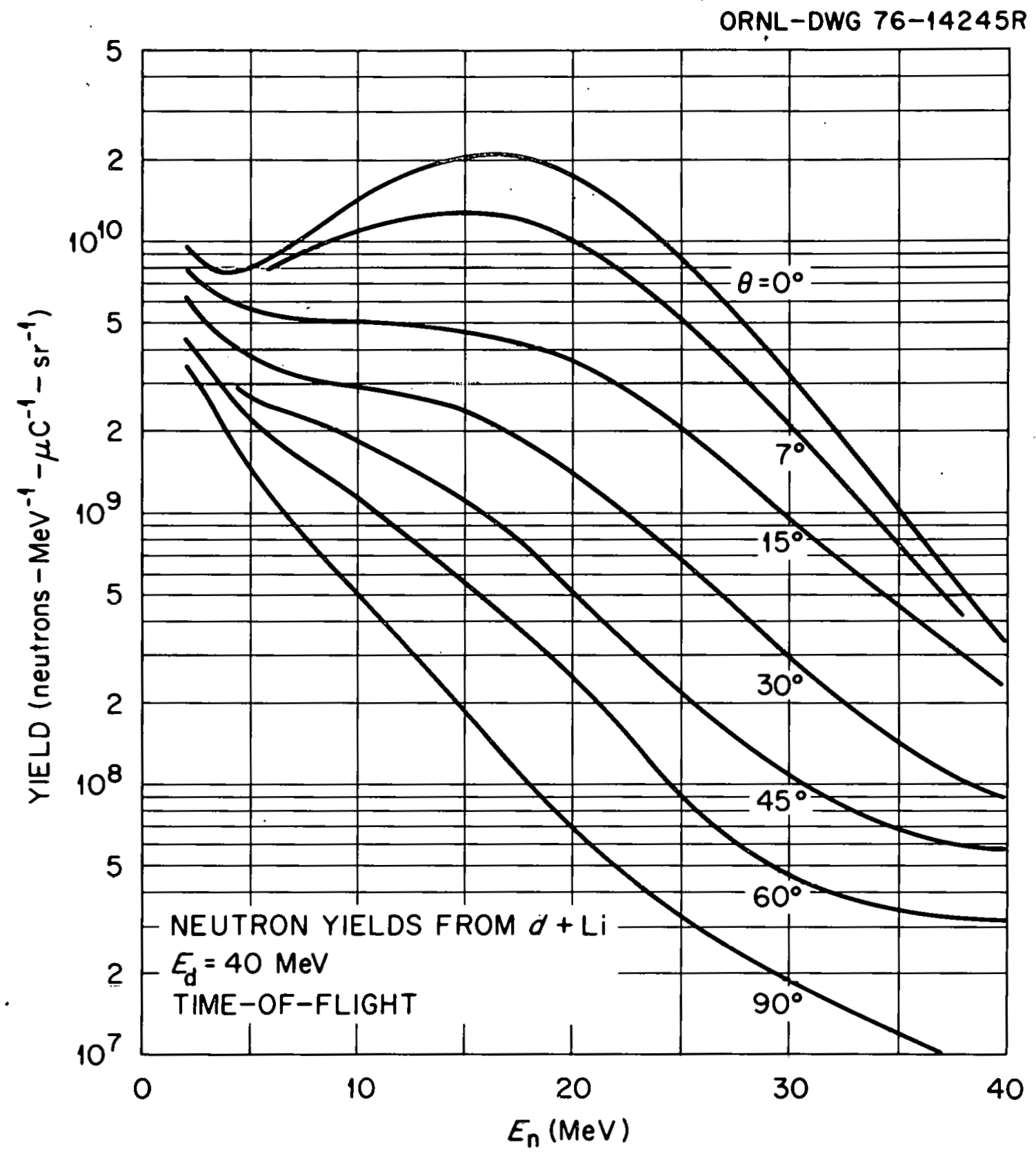

Fig. 11. Neutron yields from $40 \mathrm{MeV}$ deuterons on a thick Li target. The curves were obtained from time-of-flight data in the same manner a.s those for $d+B e$ (Fig. 5). 


\section{THIS PAGE \\ WAS INTENTIONALLY \\ LEFT BLANK}




\section{INTERNAL DISTRIBUTION}

$\begin{aligned} \text { 1. } & \text { T. A. Alsmiller } \\ 2-16 . & \text { C. B. Fulmer } \\ 17 . & \text { T. A. Gabriel } \\ 18 . & \text { E. E. Gross } \\ 19 . & \text { J. A. Horak } \\ 20 . & \text { L. H. Jenkins } \\ 21-25 . & \text { C. A. Ludemann } \\ 26 . & \text { F. C. Maienschein } \\ 27 . & \text { C. J. Mc Hargue } \\ 28 . & \text { O. B. Morgan } \\ 29 . & \text { J. B. Roberto } \\ 30 . & \text { M. T. Robinson } \\ 31 . & \text { M. W. Rosenthal }\end{aligned}$

\author{
32-66. M. J. Saltmarsh \\ 67. R. T. Santoro \\ 68. J. L. Scott \\ 69. D. Steiner \\ 70. P. H. Stelson \\ 71. J. 0. Stielger \\ 72-76. R. C. Styles \\ 77. F. W. Wiffen \\ 78. F. W. Young \\ 79. A. Zucker \\ 80-81. Central Research Library \\ 82. Document Reference Section \\ 83. Patent office \\ 84-85. Laboratory Records \\ 86. Laboratory Records - RC
}

\section{EXTERNAI, DISTRIBUTION}

87. H. H. Barscha11, University of Wisconsin, Physics Department, Madison, Wisconsin 53706.

88. R. L. Brodzinski, Battelle Pacific Northwest Laboratory, P. 0. Box 999, Richland, WA 99352.

89. M. Cohen, Division of Controlled Thermonuclear Research, USERDA, Washington, D.C. 20545.

90. D. R. Doran, Hanford Engineering Development Laboratory, P. 0. Box 1970, Richland, WA 99352.

91. A. N. Goland, Brookhaven National Laboratory, Upton, NY 11973.

92. P. Grand, Brookhaven National Laboratory, Upton, NY 11973.

93. L. R. Greenwood, Argonne National Laboratory, 9700 South Cass Avenue, Argonne, IL 60439.

94. G. Logan, Lawrence Livermore Laboratory, University of California, P. 0. Box 808, Livermore, CA 94550.

95. G. R, Odette, University of California at Santa Barbara, Santa Barbara, CA 93106.

96. D. Parkin, Los Alamos Scientific Laboratory, CMB-8, Los Alamos, NM 87544.

97. P. J. Persiani, Argonne National Laboratory, 9700 South Cass Avenue, Argonne, IL 60439.

98. C. M. Van Atta, Lawrence Livermore Laboratory, University of California, P. 0. Box 808, Livermore, CA 94550.

99. R. A. Van Konynenburg, Lawrence Livermore Laboratory, University of California, P. 0. Box 808, Livermore, CA 94550.

100. H. H. Yoshikawa, Hanford Engineering Development Laboratory, P. 0. Box 1970, Richland, WA 99352 .

101. K. M. Zwilsky, Division of Controlled Thermonuclear Research, USEREA, Washington, D.C. 20545. 
102. Director of Research and Technical Support, USERDA, ORO.

103-129. Technical Information Center, ERDA, ORO. 


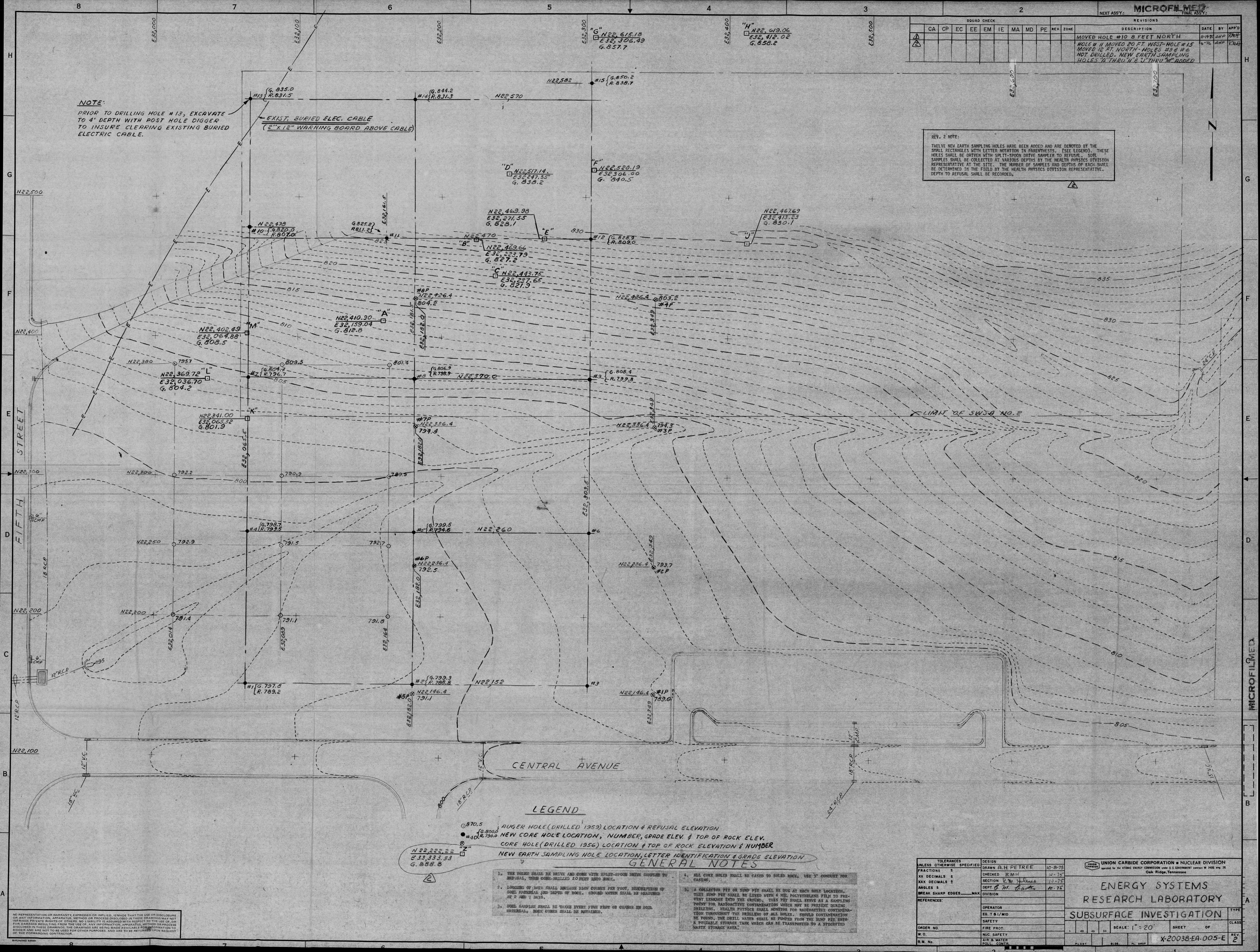

